\title{
Axial Flow Turbine Concept for Conventional and e-Turbocharging
}

\author{
Author, co-author (Do NOT enter this information. It will be pulled from participant tab in \\ MyTechZone) \\ Affiliation (Do NOT enter this information. It will be pulled from participant tab in MyTechZone)
}

\begin{abstract}
Engine downsizing has established itself as one of the most successful strategies to reduce fuel consumption and pollutant emissions in the automotive field. In this regard, a major role is played by the turbocharging, allowing to increase engine power density, and so reducing engine size and weight. However, the need for turbocharging imposes some issues to be solved. In the attempt of mitigating turbo lag and poor low-end torque, many solutions have been presented in the open literature so far, such as: low inertia turbine wheels and variable geometry turbines; or even more complex concepts such as twin turbo and electrically assisted turbochargers. None of them appears as definitive, though.
\end{abstract}

As possible way of reducing turbine rotor inertia, and so the turbo lag, also the change of turbine layout has been investigated, and it revealed itself as viable option, leading to the use of mixed-flow turbines. Only recently, the use of axial-flow turbines, with the aim of reducing rotor inertia, has been proposed as well.

The current paper documents a case study involving the design of unconventional axial-flow turbocharger turbines for a 1.6 liters S.I. light-duty automotive engine. The goal of the work is to improve engine transient performance, while guaranteeing the same level of boost pressure with respect to the baseline case, i.e. engine equipped with radial-flow turbine. To do so, two possible proposals are investigated: a "conventional" turbocharger concept, say turbine and compressor mechanically coupled, is compared against an advanced turbocharging concept, say turbine and compressor electrically coupled. A single-stage axial flow turbine is employed, for both cases, to extract energy from the exhaust gas. Ad hoc preliminary turbine design tools are developed, accounting for both design point and offdesign performance. Turbocharger-engine matching is subsequently verified by means of a $1 \mathrm{D}$ engine model. Finally, results are used to derive guidelines for unconventional turbocharging turbine design.

\section{Introduction}

Over the years the quest for more and more efficient engines, to reduce fuel consumption and pollutant emissions, has led industries and researchers to investigate novel engine concepts. Spark ignition (SI) engines efficiency suffers at part load, where it is severely diminished with respect to nominal efficiency: as engine load is reduced, engine BSFC sharply rises, because of the rapid increase pumping losses, i.e. the increase of the low pressure loop area in the engine $(p-V)$ diagram. This occurrence is caused by the cross sectional area restriction at the intake operated by the throttle valve. With the aim of addressing this Page 1 of 13 issue, many solutions have been proposed and many of them are describe in details in Ref. [1]. Among these, engine downsizing has established itself as one of the most successful strategies to cope with fuel and environmental requirements. Furthermore, this tendency is also beneficial for diving cycles; in fact, the increase of engine specific load (capacity reduction) shifts the operative point towards a higher efficiency region, [2]. However, the downsizing alone would cause a torque deficiency with respect to the larger displacement naturally aspirated (NA) engine. To avoid this undesirable effect, downsizing usually goes with turbocharging.

In Ref. [3] the authors investigate the effects on fuel consumption and engine torque of several degrees of downsizing in combination with turbocharging. In spite of a simple approach, results clearly show that engine downsizing in combination with turbocharging allows to widen the best BSFC island, moving it towards lower torque and making BSFC increment with throttling smoother with respect to NA engines. Additionally, the use of turbocharging with the aim of restoring torque curve of a larger displacement engine is investigated. Whereas from medium to high speed turbocharging proved to be a suitable way of restoring the baseline torque (namely the larger displacement one), it fails at low speed, where a torque deficit still remains. The authors ascribe the so called turbo lag both at this torque deficit at low speed and turbocharger rotor inertia. Overall, results show a clear benefit linked to downsizing in combination with turbocharging, providing $20 \%$ reduction in fuel consumption at $40 \%$ downsizing.

Whilst the use of turbochargers allows the afore-mentioned advantages, it also imposes some issues to be solved. In the attempt of mitigating the turbo lag and the poor low-end torque, many solutions have been presented so far, such as: lower density material [4] [5], low inertia wheels, variable geometry turbines (VGT), variable nozzle turbines (VNT); or even more advanced concepts such as twin turbo and electrically assisted turbochargers. For a complete review on variable geometry technologies the reader is referred to [6].

Concerning electric turbocharger, several layouts have been investigated, among which eCompressor, shaft-mounted electric motor/generator and electrically split turbochargers. In Ref. [7] an electrically split turbocharger for highly boosted 2 liter gasoline engine is investigated in single and multistage configuration, accounting for several architectures too. Results show that, depending on the working condition, the turbine to compressor power ratio might change substantially, leading to area of energy storage to supply the compressor need in unbalanced regions. Nevertheless, being the power deficit at low torque largely unfavorable for the compressor along with the a too large turbine power output at high load, the authors to have deemed the single stage arrangement impractical for that size of 
engine. Conversely, the multistage arrangement is proven to be able to provide BSFC advantages. However, if a driving cycle is considered, BSFC reduction is lowered due to the abundance of very low load operative points imposed by the driving cycles.

As possible way of reducing turbine rotor inertia, and so the turbo lag, turbine layout change has been investigated as well. In fact, mixedflow turbines exhibit an enhanced swallowing capacity over the radial ones. This results in a smaller machine, so reducing turbine rotor inertia [8]. Moreover, mixed-flow turbines exhibits similar performance to those of radial type, although shifted to lower velocity ratio (BSR) [8].

Similar considerations to those concerning mixed-flow turbines swallowing capacity have led, only recently, to investigate the suitability of axial-flow turbines in turbocharging applications as well. In fact, at the same design mass flow rate, passing from radial to mixed-flow and to axial-turbines rotor inertia is progressively lowered [9]. A similar trend is observed in the location of the efficiency peak, which, for the axial type, is shifted to even lower Blade Speed Ratio (BSR) [9]. For the sake of completeness, it is worth mentioning that, in spite of the above-mentioned pros, radial turbines for automotive turbocharging size exhibit a higher efficiency peak, as well as a wider BSR area where these values are attained [9].

Early studies on axial-flow turbine turbochargers showed very promising results, such as those conducted by Honeywell on the "Dual Boost concept", in which a double sided compressor is coupled with an axial turbine [10]. Authors claim a steady-state performance comparable with that of traditional turbochargers, while providing a rotor inertia reduction of $50 \%$. In [10] the advantage of having higher efficiency at very low BSR is also pointed out: in fact, the exhaust pulse may begin at very low BSR values, hence positive effects are expected on the energy extraction. Furthermore, tests on real engine showed that while the target torque is attained, time to torque response at low speed is substantially improved.

Published literature also reports about different configurations developed at Brunel University London in which the axial turbine concept has been investigated: Axial Inflow Radial Outflow Turbine (AIROT) and Radial Inflow Axial Outflow Turbine (RIAOT). If a purely axial inflow is concerned (AIROT), i.e. turbine stator directly connected to the exhaust manifold, the axial discharge is prevented by the compressor: in this case an exhaust collector system is used to make the radial outflow possible. Whereas, if a pure axial discharge is of interest, a volute plus vaneless nozzle is used at the turbine inlet (RIAOT). The RIAOT configuration, characterized by a vaneless nozzle followed by a turbine rotor, all fed by an inlet volute, has been numerically investigated in [11] by means of 3D CFD calculations, both in fixed and VNT configuration. Whereas AIROT configuration was numerically investigated in fixed configuration in [12] and in VGT configuration by means of pivoting vanes in [13]. In both cases the turbine was equipped with a diffuser collector, whose function is twofold: collecting the flow, and so allowing the radial discharge, while recovering residual kinetic energy at rotor outlet, so increasing turbine expansion ratio. Results of 3D CFD provided good steady-state efficiency values for both RIAOT and AIROT. In [11], [12] and [13] turbine maps were plugged in the $1 \mathrm{D}$ engine model and turbochargerengine matching was investigated. Results showed that steady-state target torque was guaranteed, proving the fluid-dynamic suitability of the concept. Furthermore, VNT and VGT studies showed encouraging results, suggesting that nozzle position - vaneless nozzle or stator vanes - could be an additional parameter for engine torque control. Overall, both options were considered successful, although some advantages from fluid-dynamic view point of the AIROT over the RIAOT are expected, namely: the lack of the upstream volute, lowering the exhaust path length, is expected to alleviate the negative effects of pulsating flow on efficiency, while synchronizing faster exhaust port with stator inlet; furthermore, larger circumferential uniformity at stator inlet is expected, as well as kinetic energy recovery. Nevertheless, the RIAOT concept advantages over the AIROT are in its reduced complexity, compactness and lower machining costs.

The current work investigates further the axial turbine concept for turbocharging applications, taking into account conventional and unconventional turbine and compressor matching. Furthermore, unlike from [11], [12] and [13] rotor inertia issue is directly faced in the design strategy, aiming at a substantial inertia improvement with respect to the baseline turbocharger, say Garret GT1548. Boundary conditions for turbine design are obtained by means of a 1D engine model approaching Ford Ecoboost performance, also used in [11], [12] and [13]. A 1D code for mean-line turbine design and preliminary sizing based on well-known correlations has been developed in MATLAB environment, along with a 1D code for turbine off-Design performance prediction. The predictive capability and accuracy of mean line code was assessed by comparing its predictions against published data. Subsequently, the mean-line design code was used to produce several turbine candidates for the two scenarios investigated, namely mechanical and electrical coupling. Following, turbine maps for the turbine candidates have been obtained by means of the offdesign performance prediction code. Turbine maps are later plugged into the engine model and results are compared against the baseline case, namely Garrett GT1548.

The paper is organized as follow: the methodology section describes the tools developed and used in this work, namely: the engine model, mean-line and off-design codes; in the results sections a discuss of the method as well as of the findings of the research activity is provided, whereas in the conclusion section final remarks and comments about different scenarios are given along with possible developments for this concepts.

\section{Methodology}

This section describes tools used for the work, code developed through this research as well as models and correlations that this work is based on.

\section{Engine Model}

The engine model, already used in previous work such as [11], is a S.I. light-duty automotive engine 4 in-line cylinders intercooled 1.61 that approaches Ford Eco Boost characteristic, whose main features are reported in Table 1 . The above-mentioned engine model, implemented in Ricardo WAVE® software, Figure 1, is turbocharged with Garrett GT1548, selected from Garret catalogue with standard procedure. Unlike from [11], turbine and compressor maps were not taken from Garret catalogue but were experimentally measured at the National Laboratory of Engine Turbocharging Technology China, Figure 2 and Figure 3, whereas turbine and compressor moment of inertia were measured at Brunel University London. Waste Gate valve (WG) opening was calibrated so to match engine torque and engine BSFC from [14]. For this purpose, a PID control was implemented in model. In Figure 4 a comparison of engine model results against engine data is presented; solid lines represent engine data from [14], whereas symbols represent engine model results. As one can notice, almost perfect agreement was obtained between engine model and engine data.

Page 2 of 13 
Table 1. Engine data [14]

\begin{tabular}{|l|l|}
\hline Displaced volume & $1596 \mathrm{cc}$ \\
\hline Stroke & $81,4 \mathrm{~mm}$ \\
\hline Bore & $79 \mathrm{~mm}$ \\
\hline Compression ratio & $10: 1$ \\
\hline Number of Valves & 4 \\
\hline Torque & $240 \mathrm{Nm} @ 1600 \mathrm{rpm}$ \\
\hline
\end{tabular}

Table 2. Turbine design boundary conditions from 1d engine simulation

\begin{tabular}{|l|l|l|l|}
\hline Engine Speed [RPM] & 5000 & 4000 & 3000 \\
\hline $\mathrm{p}_{01[\mathrm{bar}]}$ & 2,92 & 2,48 & 1,99 \\
\hline $\mathrm{T}_{01}[\mathrm{~K}]$ & 1088,95 & 1077,22 & 1060,69 \\
\hline $\mathrm{p}_{3}[\mathrm{bar}]$ & 1,42 & 1,26 & 1,16 \\
\hline$\Omega[\mathrm{RPM}]$ & 143349 & 140338 & 120727 \\
\hline$\dot{\mathrm{m}}_{\text {turb }}[\mathrm{kg} / \mathrm{s}]$ & 0,0918 & 0,0773 & 0,0586 \\
\hline
\end{tabular}

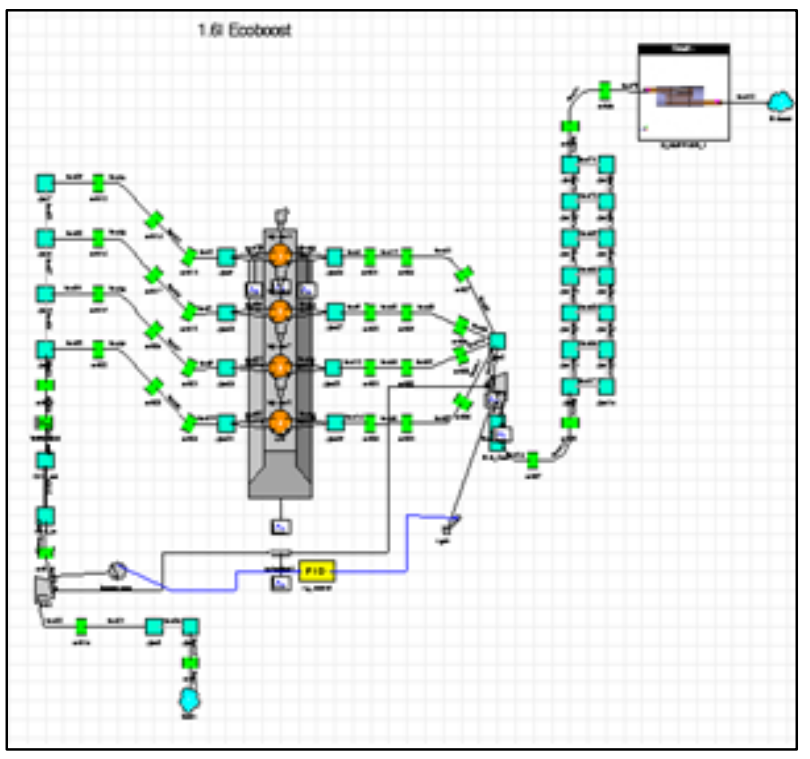

Figure 1. 1D Engine model in Ricardo Wave ${ }^{\circledR}$ environment

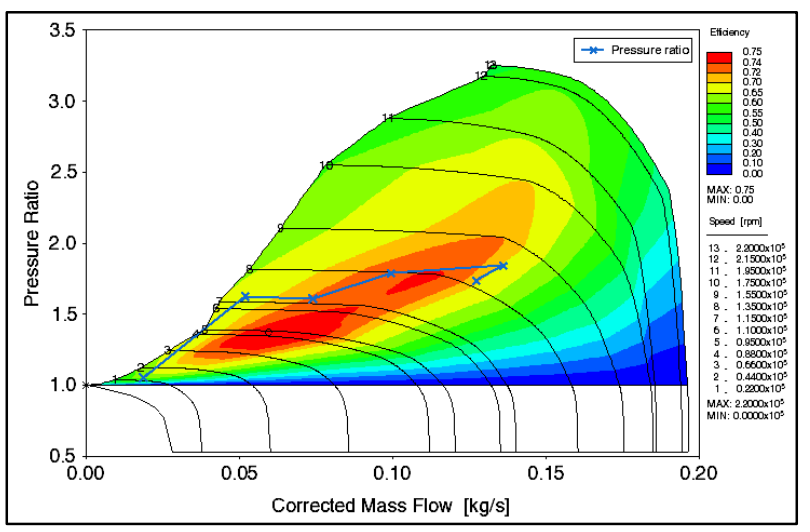

Figure 2. GT1548 Compressor map

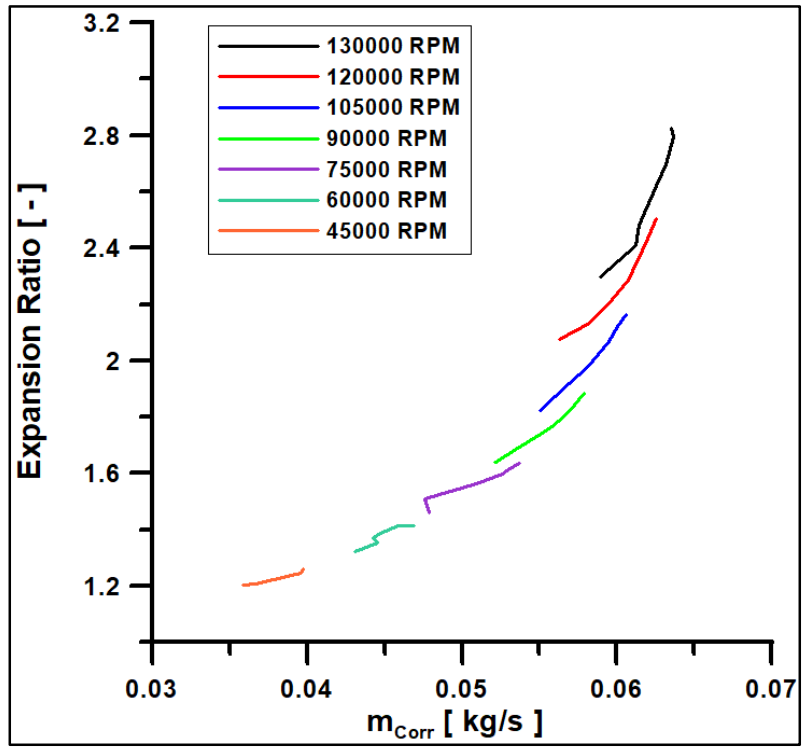

Figure 3. GT1548 Turbine map

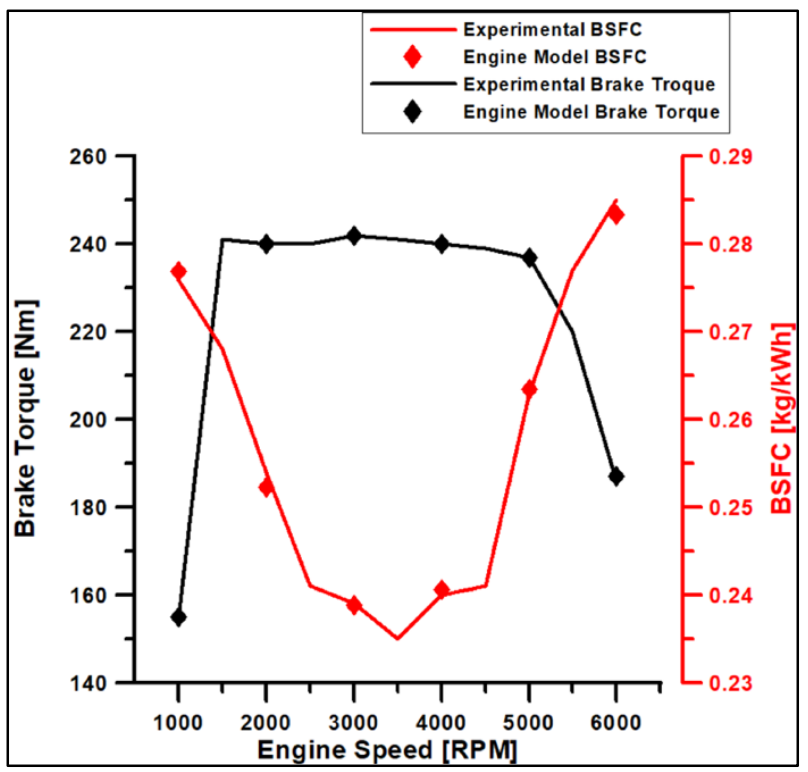

Figure 4. Engine model results (symbols) vs engine data [14] (solid lines)

Additionally, Figure 5 shows the ratio of the mass flow rate bypassed through the wastegate vale to the total exhaust gas. This amount will be of key importance for a preliminary estimate of the power output increase from the turbine in a hybrid turbocharging layout.

In Figure 6 an example of ( $\mathrm{p} \mathrm{V}$ ) diagram from engine model results for two working conditions is depicted: as one can notice, quite regular trends are achieved as well as no abnormal combustion arises. For details about the engine model the reader is referred to [11]. The engine model was run at Wide Open Throttle (WOT) from 1000 to $6000 R P M$ and results,

Page 3 of 13 


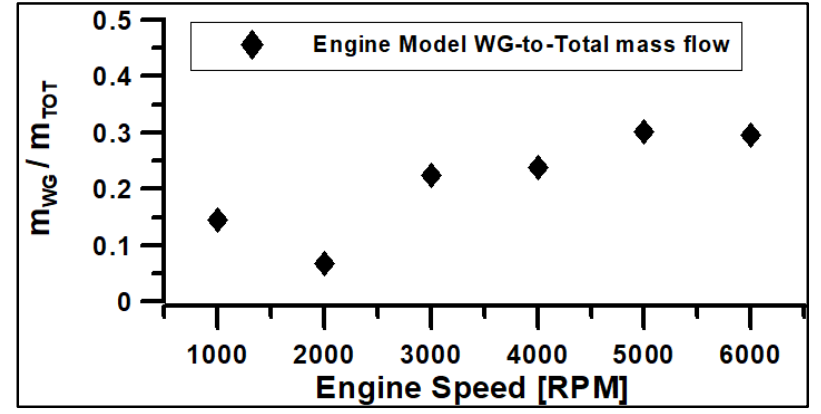

Figure 5. Waste-gated mass flow to total exhaust mass flow

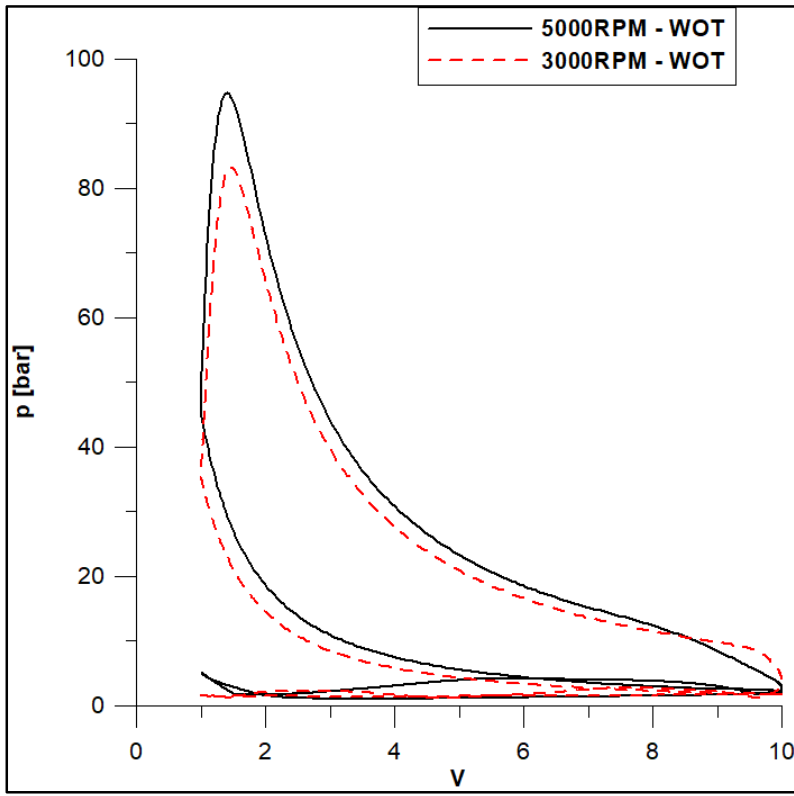

Figure 6. (pV) diagram for two working conditions: 3000RPM - WOT (red dashed line); 5000RPM - WOT (black solid line)

\section{Mean-line Design Code}

A 1D mean-line design code has been developed at Federico II University for the current activity. The program is implemented in MATLAB environment and allows to perform the mean line design of an axial turbine stage, computing velocity triangles, power output and efficiency, as well as sizing the meridional section of the machine, e.g. vane and blade chord, channels height, along with optimum blade and vane numbers. The user is asked to provide turbine Boundary Conditions (BC), along with a few data which are treated as free design variables. In Figure 7 a schematic representation of the code is provided. Based on first guess stator and rotor efficiencies, thermofluid-dynamics properties are computed at inlet and outlet of each row, along with power output and work exchange, total-to-static and totalto-total efficiencies. Channels height are sized such that they can host the design mass flow rate; mean diameter $D_{m}$ is found by establishing the optimum kinematic ratio. Once the flow angles are known, the metal angles are determined by means of Ainley and Mathieson (AM) deviation correlation (included in AM correlation system [15]) used iteratively in and undirect manner. Blade and vane number are found by means of the well-known Zweifel Criterion [16]. Stator and rotor stagger angles are subsequently found by means of Kacker and Okapuu (KO) chart included in KO correlation system [17]. Finally, loss calculation is performed according to $\mathrm{KO}$ correlation system for mean Page 4 of 13 line prediction, which is an extension of AM [15] and DC [18] correlations.

Once loss components are known for both rows, a pressure loss coefficient is computed for stator and rotor: these are used to recomputed stator and rotor blading efficiencies. These values are compared against the ones assumed by the user and, if the difference is beyond a certain threshold (set by the user), the procedure is repeated exploiting efficiencies values just computed. The program iterates up to convergence on both stator and rotor efficiencies is reached.

Once convergence is reached and all quantities have been computed, rotor moment of inertia is roughly estimated. Moment of inertia is computed decomposing turbine rotor disc in sub-elements for which moment of inertia is known. It is worth mentioning that, being the detailed blade shape still unknown, and so a precise esteem unfeasible, the moment of inertia has been over-estimated considering blade thickness in the span-wise direction constantly equal to its maximum value computed according to [17], where a chart for maximum thickness calculation (based on row turning angle) is provided.

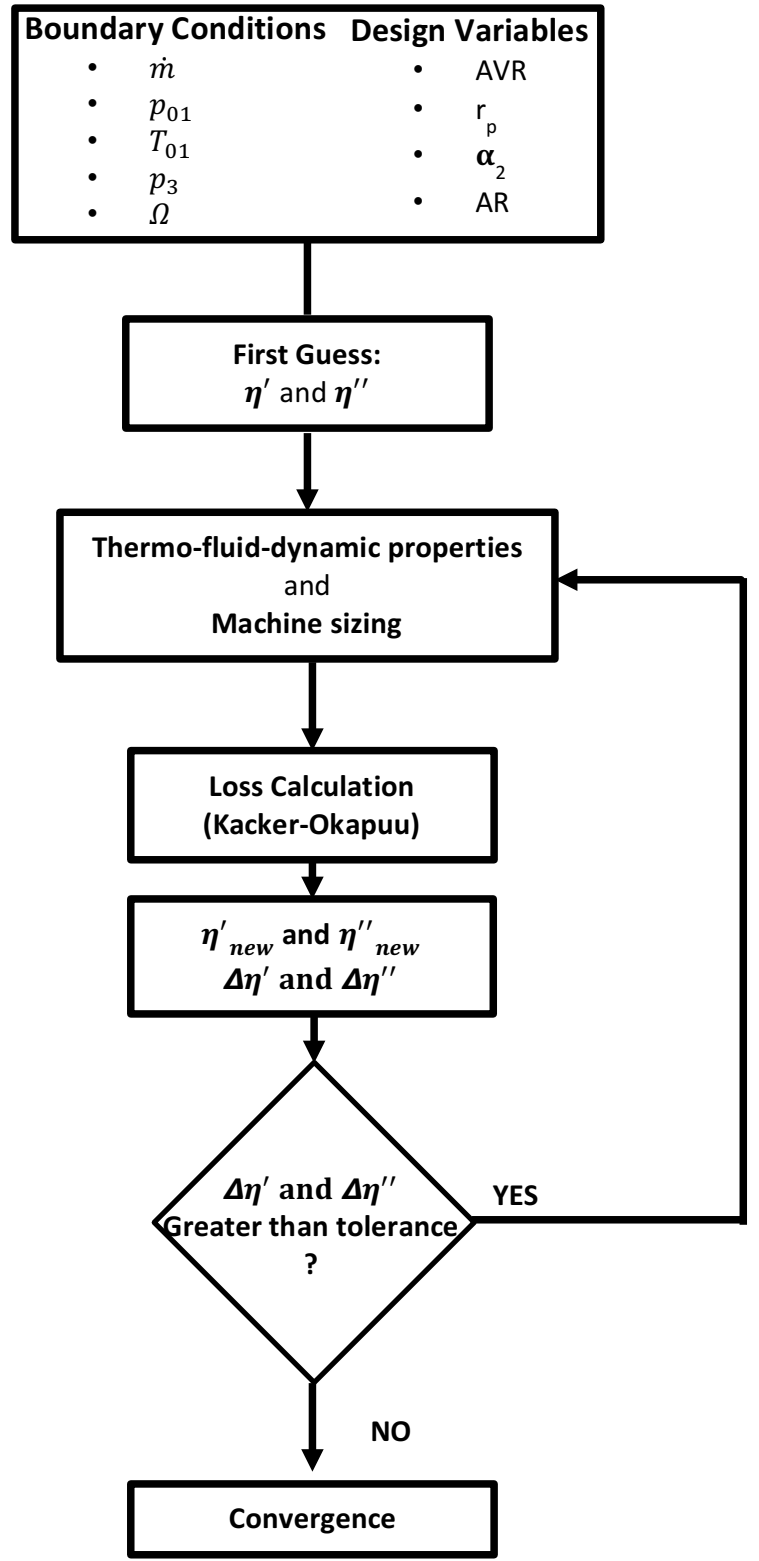

Figure 7. Mean line design code schematic 


\section{Off-Design Performance Prediction Code}

Turbine map computation by means of accurate $3 \mathrm{D}$ calculations is a very expensive task in terms of computational time. To bound the design space and to evaluate most promising candidates, a cheaper tool is required to test them with reasonable CPU time. With this aim, an off-design program has been written based on $\mathrm{KO}$ correlation system. However, $\mathrm{KO}$ correlation is not intended to account for off-design points; for this reason, $\mathrm{KO}$ correlation system was integrated with Benner-Sjolander-Moustapha (BSM) profile loss incidence correlation [19], which allows to compute the extra loss due to off-design incidence. Whereas Moustapha-Kacker-Tremblay (MKT) correlation [20] is used for off-design secondary loss evaluation. In the following paragraph, the code structure is presented.

\section{Code Structure}

A schematic representation of code steps used to solve each row is provided in Figure 8. Turbine mass flow rate, turbine inlet total pressure, turbine inlet total temperature and rotational speed are required by the code as $\mathrm{BC}$, along with turbine geometrical features. Two loops are established to solve each row: at the first iteration the row is assumed to be isentropic (conservation of total pressure), the static outlet pressure is retrieved iteratively by the efflux function $\psi$ through a nozzle; bracketing method is used to find the root of the function $\left(\psi_{\text {recomputed }}-\psi_{\text {target }}\right)$ in the unknown outlet static pressure, being efflux function computed as:

$$
\begin{gathered}
\psi_{\text {target }}=\frac{\dot{m} a_{0}}{p_{\text {tot ex }} * A_{\text {nozzle }}} \\
\psi_{\text {recomputed }}=\left\{2 \frac{\gamma^{2}}{\gamma-1}\left(\frac{p}{p_{\text {tot }}}\right)^{\frac{2}{\gamma}}\left[1-\left(\frac{p}{p_{\text {tot }}}\right)^{\frac{\gamma-1}{\gamma}}\right]\right\}^{\frac{1}{2}}
\end{gathered}
$$

At each iteration, outlet flow angle is updated according to AM deviation angle correlation, [15]. Losses are computed according to KO, BSJ, MKT correlations [17], [19] and [20] retrieving a total pressure loss coefficient, which is used to recompute the outlet total pressure. The procedure is repeated up to convergence on outlet total pressure is reached. Mean radius change through the rotor is treated assuming rothalpy conservation. Repeating the procedure for stator and rotor, turbine outlet static pressure can be determined as well as outlet power and efficiency.

\section{Code Validation}

Machine size effects are of course taken into account in KO correlation system, particularly for Tip Clearance (TC) loss and secondary flows, as well as Reynolds number effect is accounted. Nevertheless, KO correlation system has been developed based on machine of much larger size than that of interest in this work and to the authors' knowledge its accuracy has never been assessed for such a small scale. For this reason, the evaluation of its predictive capability for small scale machines has been deemed of paramount importance. Unfortunately, to the authors' knowledge only few published studies are available for small axial machines and most of them are only numerical. However, a code validation has been carried out comparing code prediction against turbine data taken from [13]. Results shows that the code predicts with reasonable accuracy total-to-total and totalto-static efficiency. Particularly, total-to-static efficiency prediction is in most of the investigated cases well below $\pm 5 \%$ relative difference. This threshold is exceeded only at off-design conditions extremely far Page 5 of 13 from the design-point, i.e. combination of expansion ratio about $60 \%$ of the design one and rotational speed about $20 \%$ of the design one. Similar results are observed for the total-to-total efficiency, with relative difference generally below $\pm 3 \%$. Again, this threshold is exceeded only in a very limited region, far away from the design point as mentioned above.

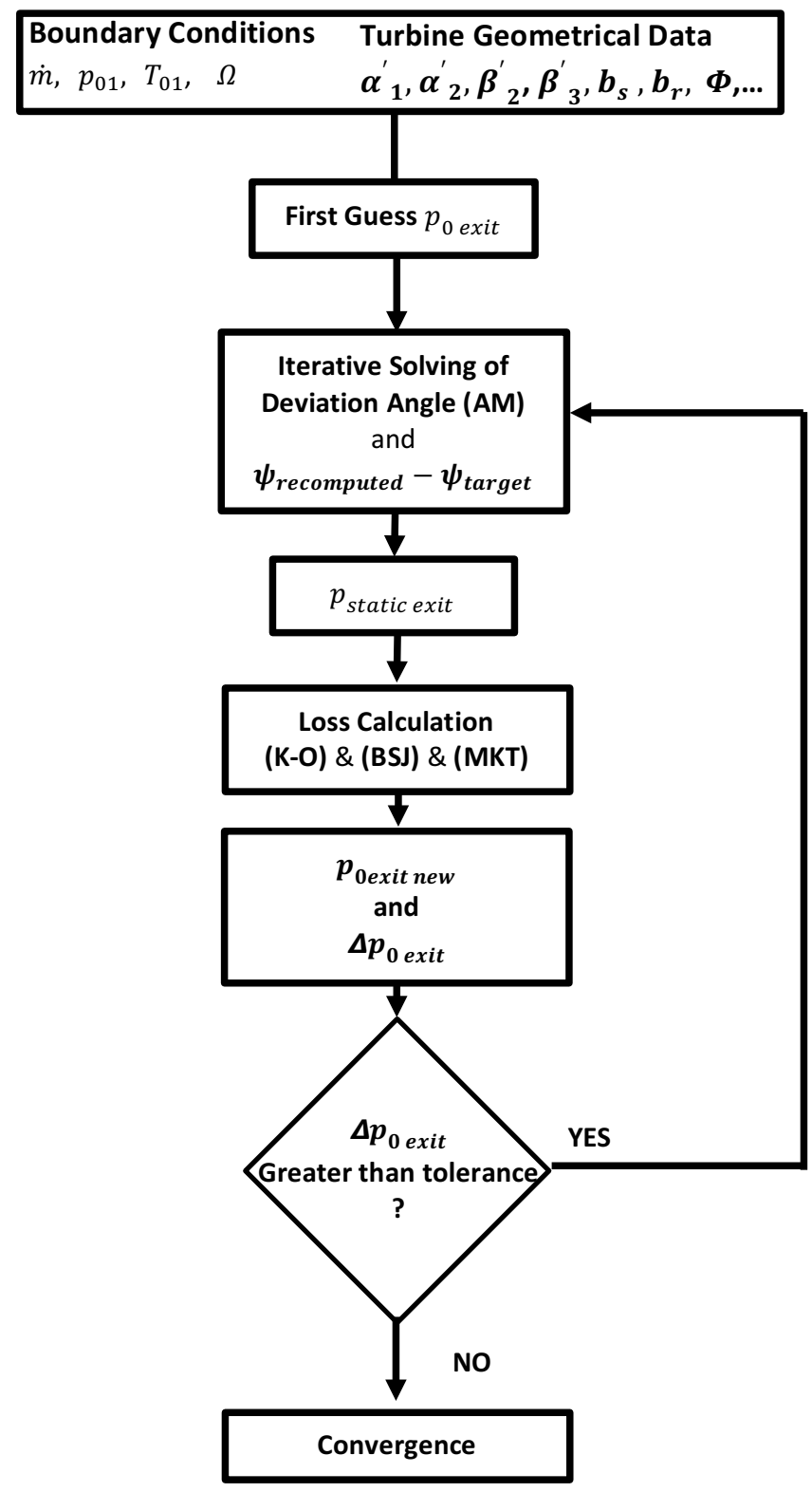

Figure 8. Mean line off-design code for a single row

\section{Turbine Parametric Analysis}

Based on boundary conditions reported in Table 2, a turbine parametric analysis was performed to explore the design space. For this purpose, the mean line design code described in a previous section was used. Design variables $A V R, r_{p}, \alpha_{2}$ were varied according to the range reported in Table 3 . Two design points have been considered at 3000 , and $5000 \mathrm{rpm}$, that is to say that the parametric analysis was carried out at each of the above-mentioned design points by running the code multiple times. In Figure 9 the design space at a single design 
point is presented for the traditional turbocharger concept: each grey dot represents a new design candidate, characterized by a different combination of $A V R, r_{p}, \alpha_{2}$. On the horizontal axis the power mismatch between compressor and turbine is reported. It is worth mentioning that mechanical efficiency is also accounted in the power mismatch computation. Moreover, turbine mass flow rate computed by the engine model was kept unchanged for turbine power calculation. On vertical axis moment of inertia change between GT1548 turbine and the axial turbine candidates is presented made non-dimensional by the GT1548 turbine inertia. Finally, design candidates that provides a moment of inertia reduction (with respect to the baseline turbine) while guaranteeing no decay in turbine performance are highlighted in black, showing that there is actually room for improvements.

Table 3. Turbine design variables ranges for parametric analysis

\begin{tabular}{|l|l|}
\hline AVR [-] & $1.0-1.3$ \\
\hline$r_{p}[-]$ & $0.1-0.7$ \\
\hline$\alpha_{2}\left[^{\circ}\right]$ & $40-70$ \\
\hline
\end{tabular}

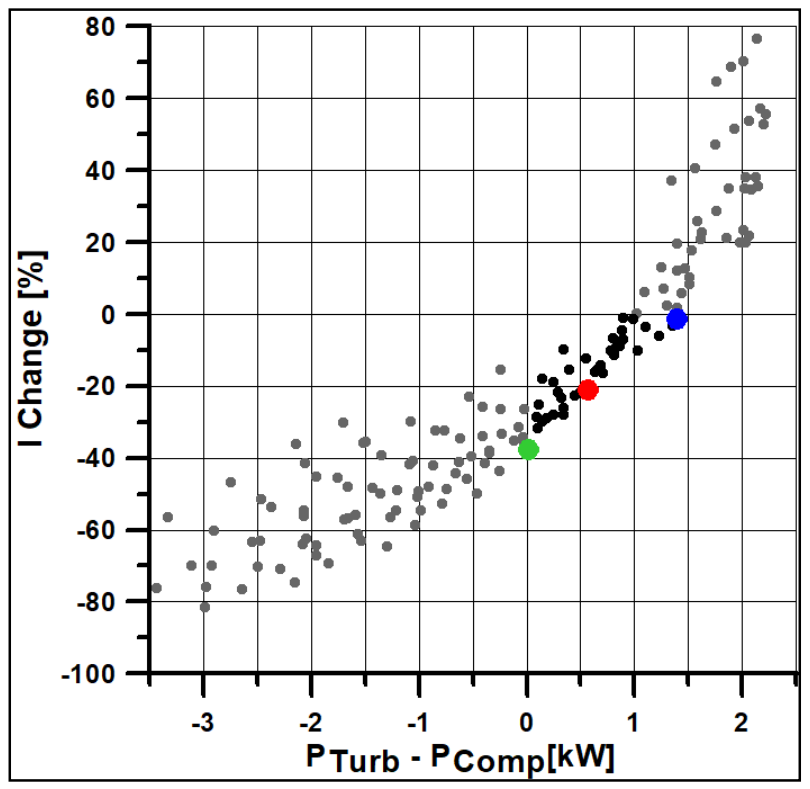

Figure 9. Turbine Design space at 5000RPM -WOT

Additionally, the design spaces in Figure 9 and Figure 10 put clearly into evidence the chance to proceed with a multi-objective optimization. Actually, the turbine output and its moment of inertia exhibit conflicting trends and a Pareto front can be easily detected in both figures. Consequently, several solutions offering a reasonable compromise between the two objectives may be selected. Based on the above considerations, three candidates have been chosen and their location on the design space is shown by means of color dot.

The first candidate -blue dot- is chosen such that it exhibits high efficiency and almost the same inertia of GT1548 turbine, the second candidate -red dot- is chosen such that it can provide the good efficiency while lowering turbine rotor inertia; and a third candidate green dot- characterized by the largest turbine rotor inertia reduction compatible with the constraint of providing the same power output of the baseline case (under the same boundary condition), so to leave possibly unchanged engine-turbocharger matching at design point. Design variables combination for the three choices is reported in Table 4 along with best efficiency value and Inertia change. Figure 12 and

Page 6 of 13
Figure 11 depict velocity triangles at mid-span, and meridional sections for the new design candidates.

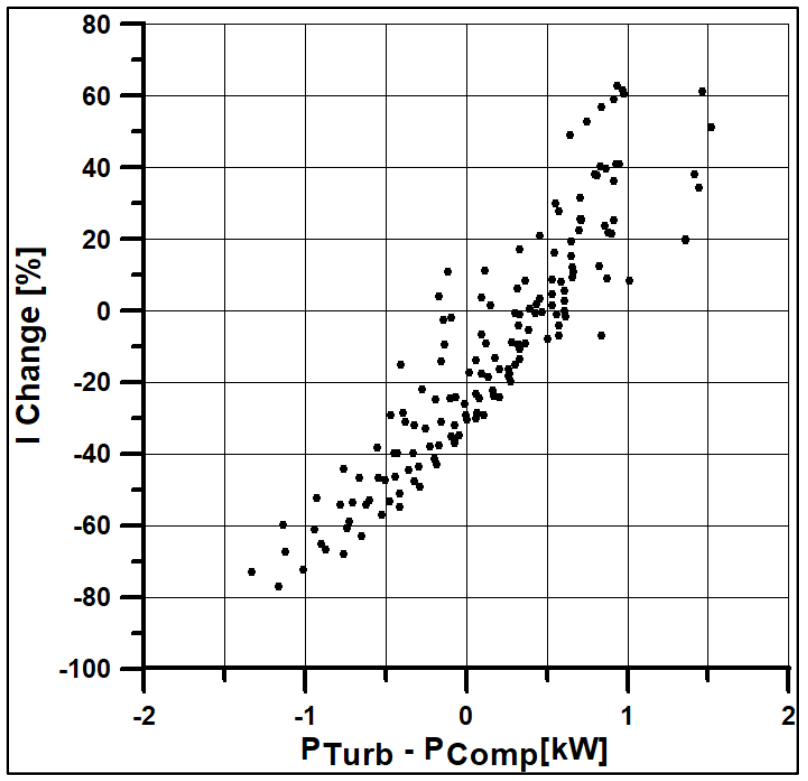

Figure 10. Turbine Design space at 3000RPM -WOT

Table 4. Design variables, total-to-static efficiency and inertia change for the selected turbines

\begin{tabular}{|l|l|l|l|}
\hline Test Cases & \multicolumn{1}{|c|}{ I } & \multicolumn{1}{|c|}{ II } & III \\
\hline AVR [-] & 1.3 & 1.3 & 1 \\
\hline$r_{p}[-]$ & 0.5 & 0.45 & 0.2 \\
\hline$\alpha_{2}\left[^{\circ}\right]$ & 65 & 60 & 55 \\
\hline$\eta_{t s}[\%]$ & 66.7 & 61.6 & 58.1 \\
\hline$\Delta I[\%]$ & -1.2 & -21 & -37.6 \\
\hline
\end{tabular}

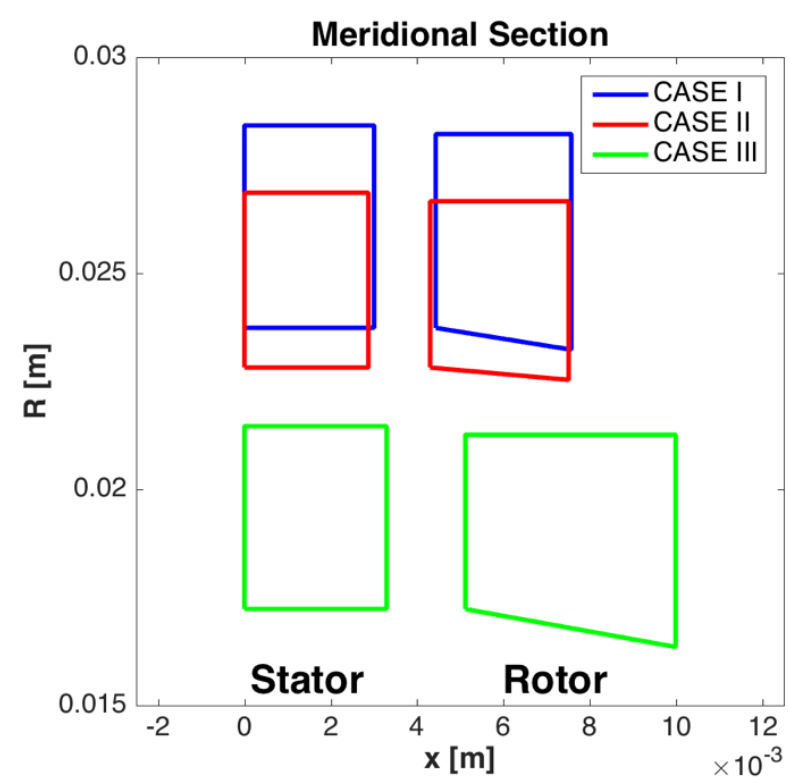

Figure 11. Meridional section for the three turbine candidates: blue) Case I; red) Case II; green) Case III 


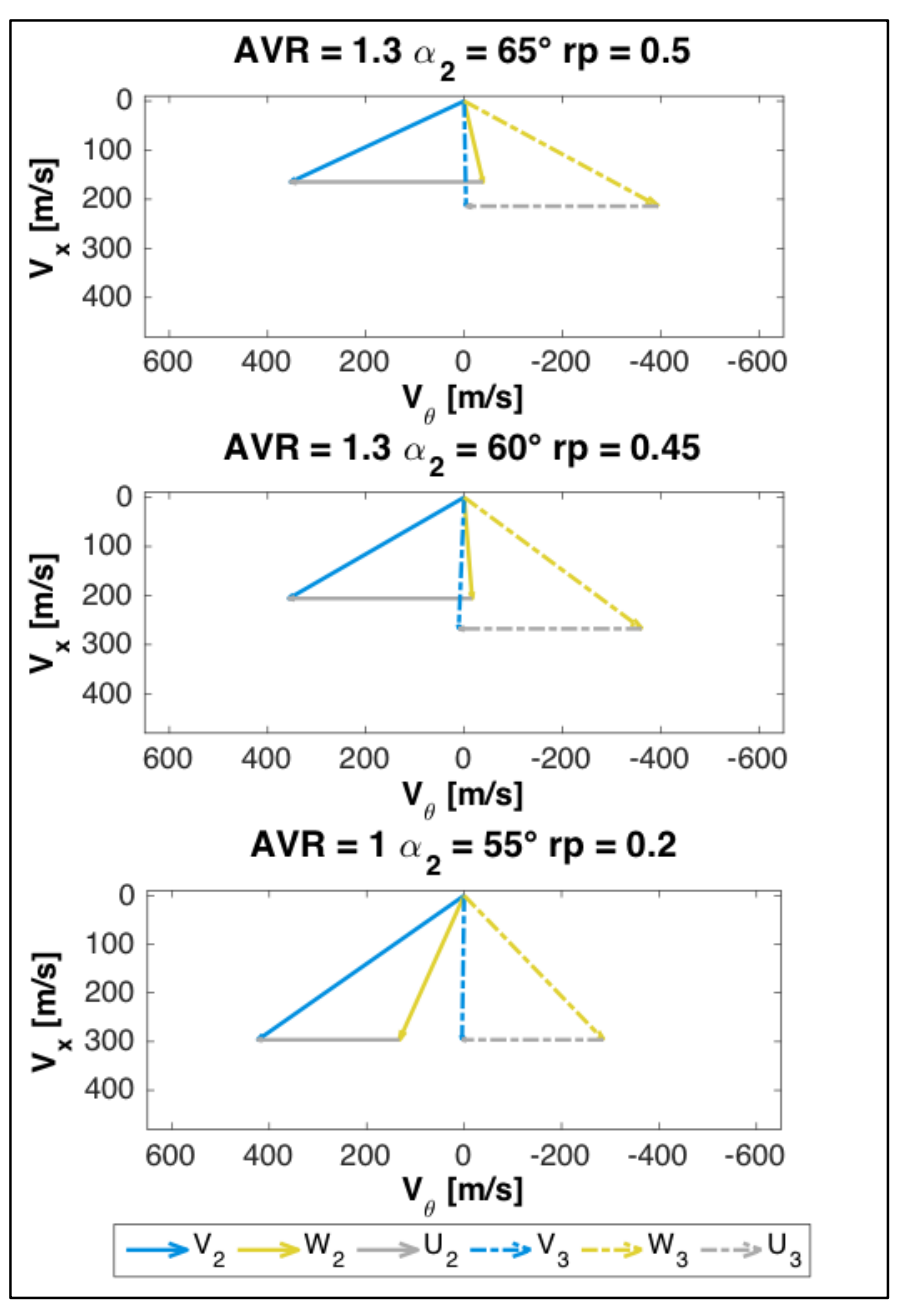

Figure 12. Design point velocity triangle for the three turbine candidates: top) Case I; middle) Case II; bottom) Case II

\section{Turbine Maps}

In order to investigate new turbine candidates performance at offdesign conditions as well as their matching with the engine, turbine maps have been generated by means of the off-design performance prediction code described previously. Two turbine maps are depicted in Figure 13 and Figure 22 as samples, showing the different iso-speed trends given by the different combination of the design variables.

Turbine maps for the three design candidates were later plugged into the engine model and steady-state as well as transient performance were investigated.

Comments on the turbine candidates along with a discussion of the turbocharger-engine matching and global performance achieved by means of new turbines are provided in the next section.

If comparing the radial turbine map in Figure 13 with those of the axial flow turbines, some different results can be expected in the engine turbocharger matching at steady - state. Similarly, the trend of characteristic curves will play a key role, together with the rotor moment of inertia, in the development of any transient process.

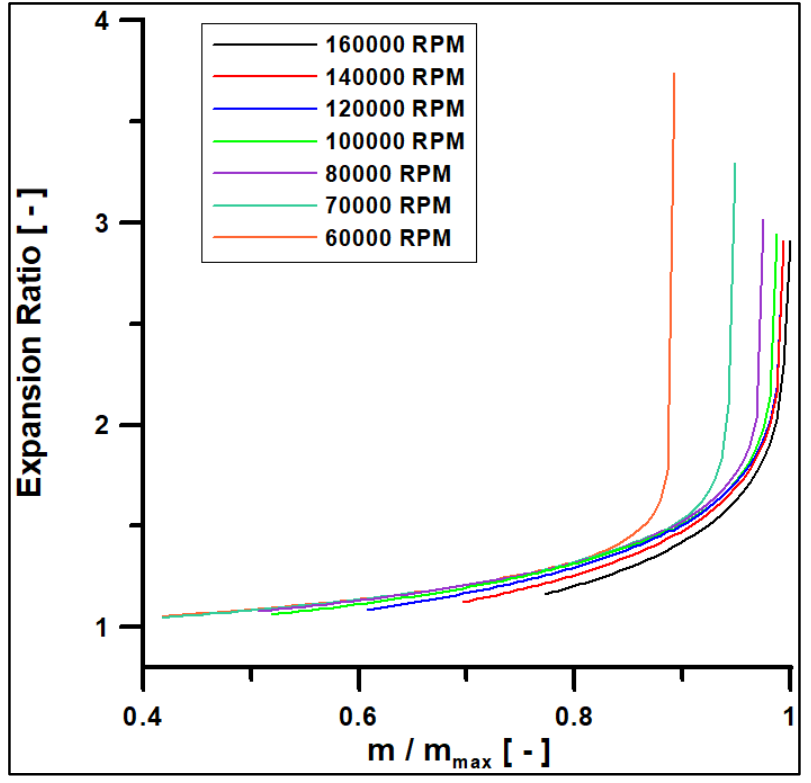

Figure 13. Turbine performance map for case I configuration

\section{Results and Discussion}

\section{Turbine-Compressor Mechanical Coupling Case}

It is worth-noting that cases II and III show a lower total-to-static efficiency with respect to the first one. However, this occurrence appears consistent with the velocity triangles depicted in Figure 12. In fact, as one can notice, axial velocities at rotor outlet for case II and case III are much higher than that of case I, resulting in a larger energy loss as residual kinetic energy. Nevertheless, the larger axial component allows a reduction of the flow area, so providing a more compact machine Figure 11, with advantages from the moment of inertia point of view. Finally, it should be mentioned that the turbine considered in this work would be equipped with an exhaust collector system aimed at discharging the flow radially, though not explicitly accounted in the current work so far. However, this component also offers the chance of residual kinetic energy recovery, which allows enlarging the turbine expansion ratio, increasing work extraction and so alleviating the penalty introduced by the efficiency debit [13]. In the next section the results of the turbocharger-engine matching for the case of "conventional mechanical coupling of compressor and turbine" are described.

\section{Steady-State}

After building up the maps for the new turbines, steady-state engine performance was verified by plugging the above-mentioned maps into the engine model, while leaving the same compressor as in the baseline layout, and checking torque and BSFC delivered by the engine in the new configurations. While performing this analysis, the engine model was entirely unchanged, as well as PID control calibration, except for turbine maps interpolation method, which was set to axial. The engine model was run from $1000 \boldsymbol{R P M}$ to $\mathbf{6 0 0 0} \boldsymbol{R P M}$ at WOT for the three turbines. The results are compared in terms of engine brake torque, Figure 14, and engine BSFC, Figure 15, against the baseline case (solid line). As one can notice in Figure 14, with the first and second turbines, characterized by the largest efficiency among the three selected, the target torque was ensured; whereas the engine equipped by the third one failed in delivering the desired torque at 2000 RPM at WOT. This

Page 7 of 13 
occurrence can be explained to the lower boost pressure attained at this engine regime with the third turbine (Figure 16). In fact, the boost pressure achieved by the first two turbines is basically the same as in the baseline case.

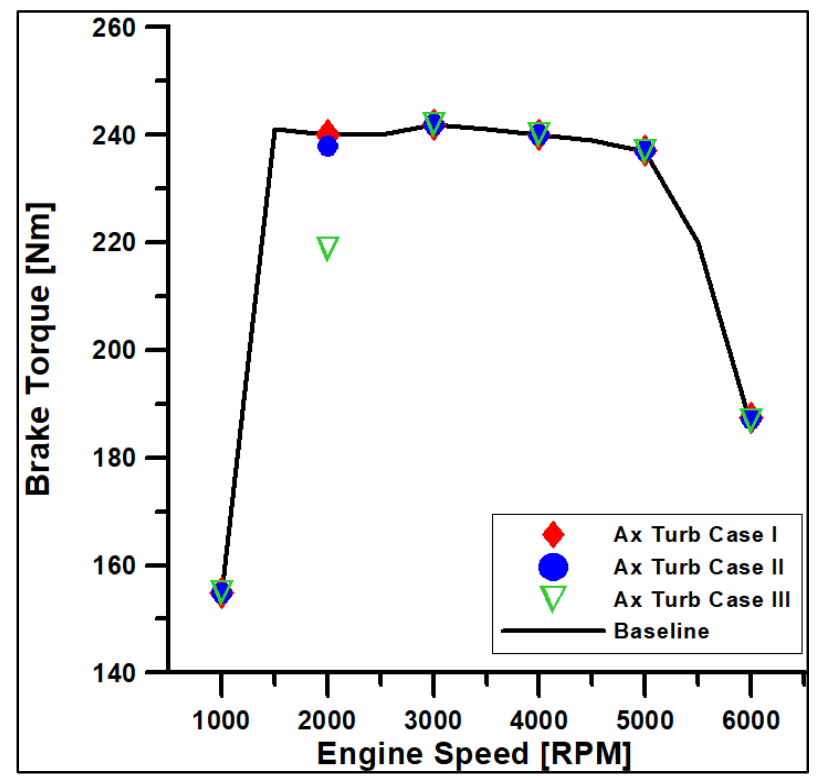

Figure 14. Engine brake torque: baseline (solid line) vs new designs

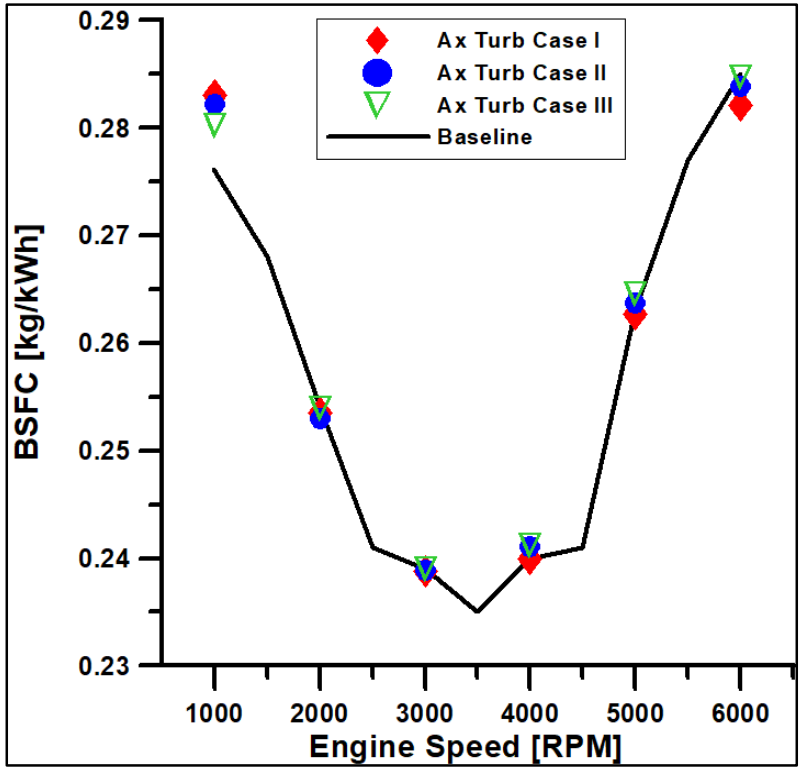

Figure 15. Engine BSFC: baseline (solid line) vs new designs

Finally, BSFC values achieved by means of the three turbines are presented in Figure 15 against those of the baseline case (solid line). As one can see, BSFC value are substantially unchanged in all the investigated conditions. Overall, steady-state calculations are considered satisfactory at least for the first two investigated cases, which proved to be a valid alternative to the baseline radial flow turbine. In fact, the first and second turbines proved to be able to preserve target torque, boost pressure and BFSC levels from steadystate point of view, so showing the suitability of the axial-flow turbine layout. Furthermore, the second investigated turbine provides a rotor moment of inertia reduction by more than $20 \%$. In order to assess the

Page 8 of 13 advantages eventually provided by the moment of inertia reduction, the first and second turbines are analyzed further from transient performance view point. In next section, details about the method used for this purpose, as well as the results obtained are provided.

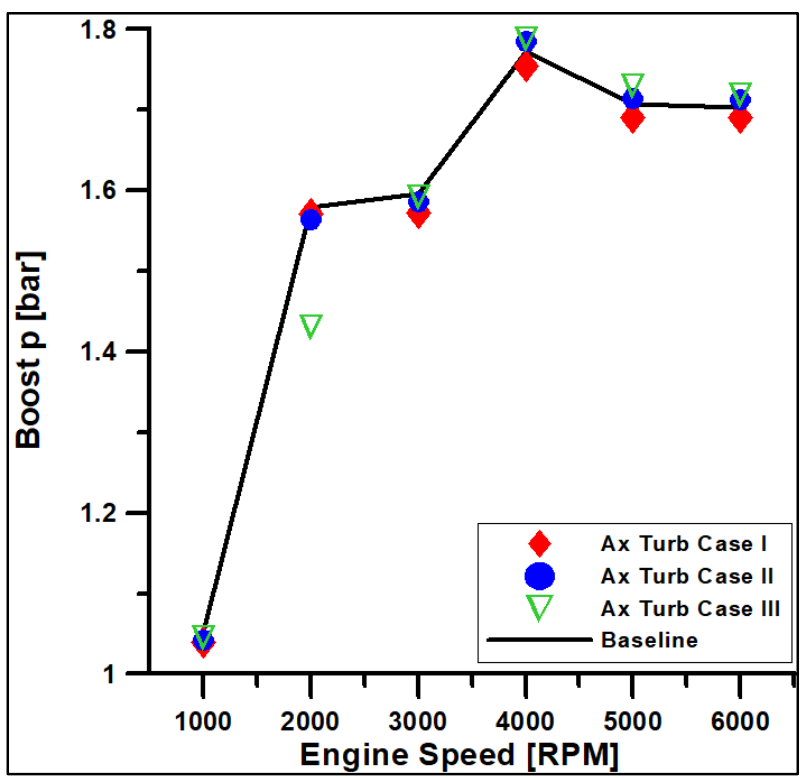

Figure 16. Boost pressure: baseline (solid line) vs new turbine candidates

\section{Transient Performance}

In the previous section the fluid-dynamic suitability of an axial flow turbine for passenger vehicle turbocharging was demonstrated. Furthermore, rotor moment of inertia issue was explicitly faced in the design procedure, showing that advantages might be achieved in this sense. In order to quantify the transient response relief achieved by the inertia reduction, transient analyses were carried out and described in the current section. Due to the limited data concerning lower engine load a simplified approach was used, that is to say transient response to rapid throttle valve opening was not carried out. The procedure used is not intended to represent a real transient operation as such of drive cycle, instead it aims at evaluating whether or not the inertia reduction is large enough to play a role over a transient operation. It should be also reminded that the transient response of the turbocharger is also affected by the new turbine maps. In addition, the transient process was analyzed in terms of behavior of the whole turbocharged engine system.

To do so, an engine speed rise from $2000 \mathrm{rpm}$ to $5000 \mathrm{rpm}$ at WOT was imposed. This approach, even if very simplified with respect to a real transient operation, allows measuring the time interval needed for passing from the instant at which new conditions are imposed to the one when the final steady-state is reached. While doing so, the same target torque and boost pressure are maintained with respect to the previous cases, as well as PID control calibration. The analysis is repeated for the baseline case and for the first and second turbines; turbocharger speed and boost pressure change are reported in Figure 17 and Figure 18. As one can notice, both turbocharger speed and boost pressure change follow very similar trends for the three cases considered (baseline and new turbines), but the whole dynamics is shifted towards the left-hand side of the charts for the new turbines. Thus, the whole engine dynamic behavior appears to be sensitive to the inertia change provided by the axial turbine, which, in combination 
with good efficiency values achieved by the new turbines, results large enough to make a difference.

With a similar approach, also a change of engine load at constant speed was investigated. Still, the method is not intended to reproduce a real transient operation, whereas it aims at investigating how long it takes for the system to reach a new steady-state after that new conditions are imposed. Engine speed was kept equal to 5000 RPM and the load was increased from about $65 \%$ to $100 \%$; results are presented in Figure 19 and Figure 20. As one can notice, results are similar to those of Figure 17 and Figure 18, showing that the system dynamics is moved towards shorter times when considering the axial flow turbines.

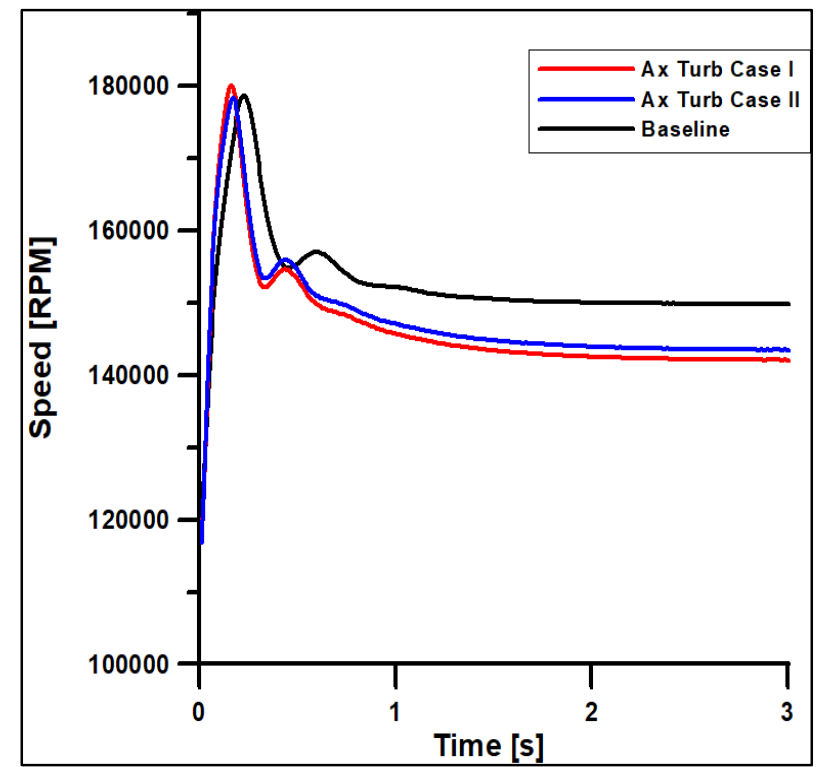

Figure 17. Turbocharger speed change over a transient from $2000 \mathrm{rpm}$ to $5000 \mathrm{rpm}$ : baseline vs new turbines

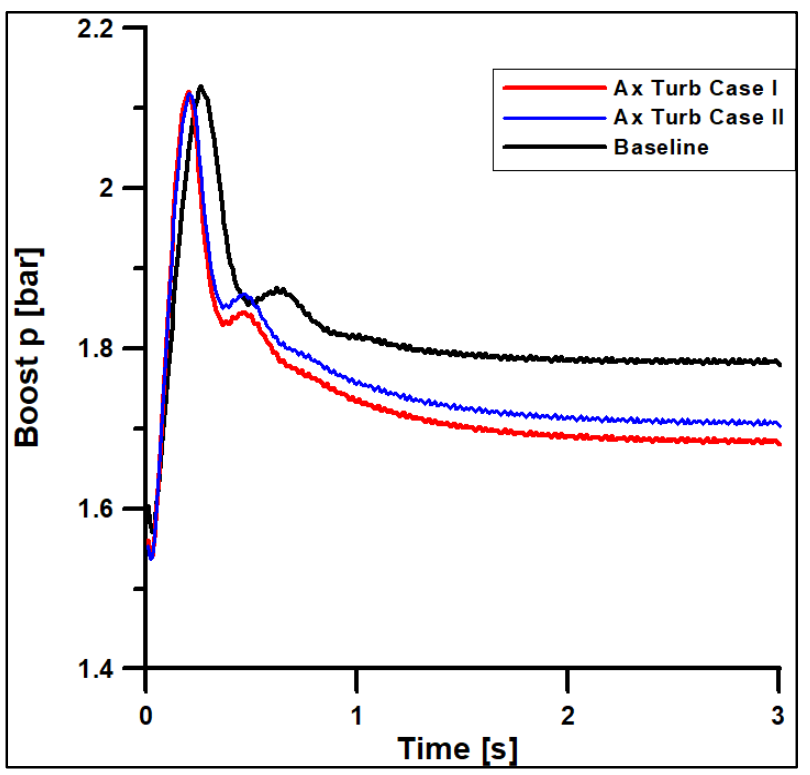

Figure 18. Boost pressure change over a transient from 2000 to $5000 \mathrm{rpm}$ : baseline vs new turbines

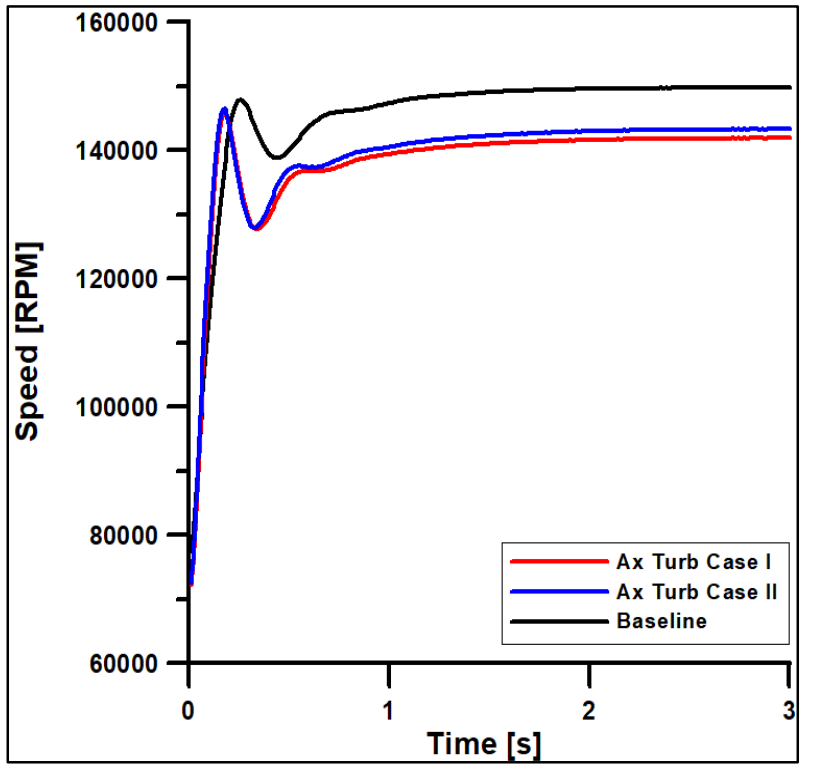

Figure 19. Turbocharger speed change over a transient from low load to full load: baseline vs new turbines

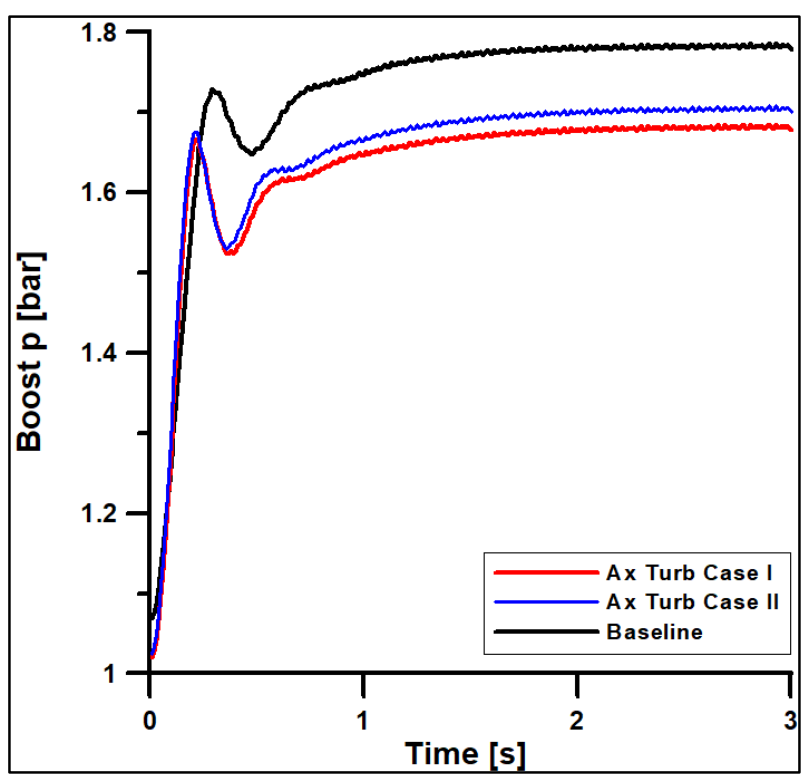

Figure 20. Boost pressure change over a transient from low load to full load: baseline vs new turbines

\section{Turbine Selection for Hybrid Turbocharging}

The same methodology as the one described in previous sections was accessed to define the design space of the axial flow turbine to be selected for employment in the hybrid turbocharging layout Figure 21. In this case, the baseline gas flow rate through the turbine was assumed to be the whole exhaust mass flow leaving the engine, so including the rate that was addressed to the waste gate for boosting control. This choice would ensure a larger power output from the turbine and, therefore, an increased rate of electric power from the generator in Figure 21. Consequently, electric energy storage would be allowed at high engine speeds or loads. The stored energy would be available, at least, in cases, of lack of mechanical power for the motor driven 
compressor and, additionally, for supplementary energy requirements form the vehicle.

The design space is represented in Figure 23 and, in this case, the more appropriate conflicting objectives to be controlled were the power output and the peripheral tip speed. Based on this assumption an acceptable compromise was detected in the case evidenced in the same Figure 23, whose main characteristics are summarized in Table 5, along with its meridional section displayed in Figure 24.

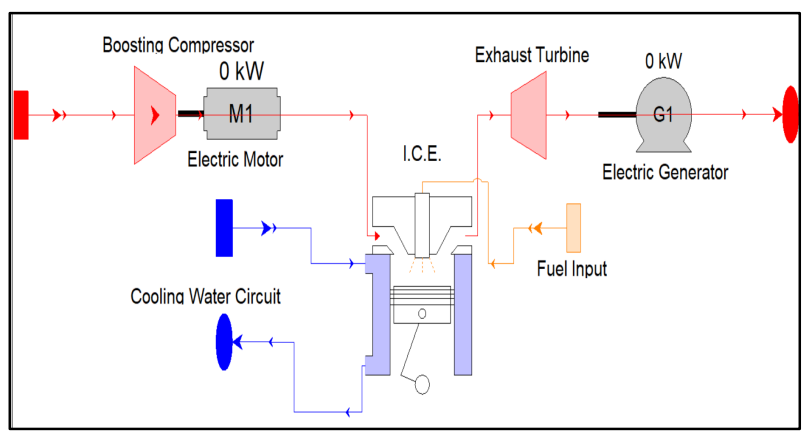

Figure 21. Engine hybrid turbocharging layout

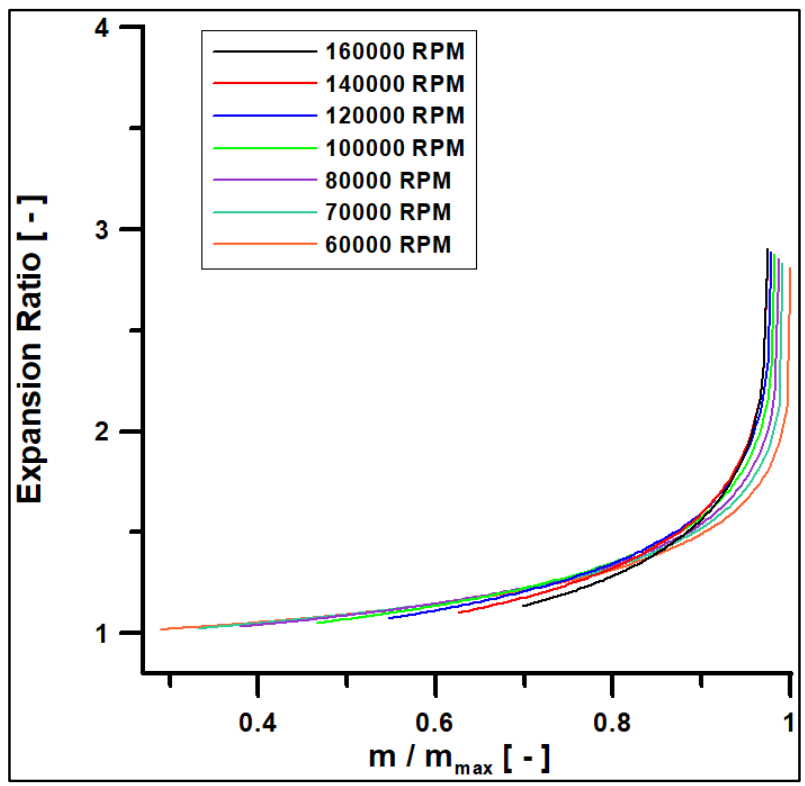

Figure 22. Turbine performance map for hybrid turbocharging case

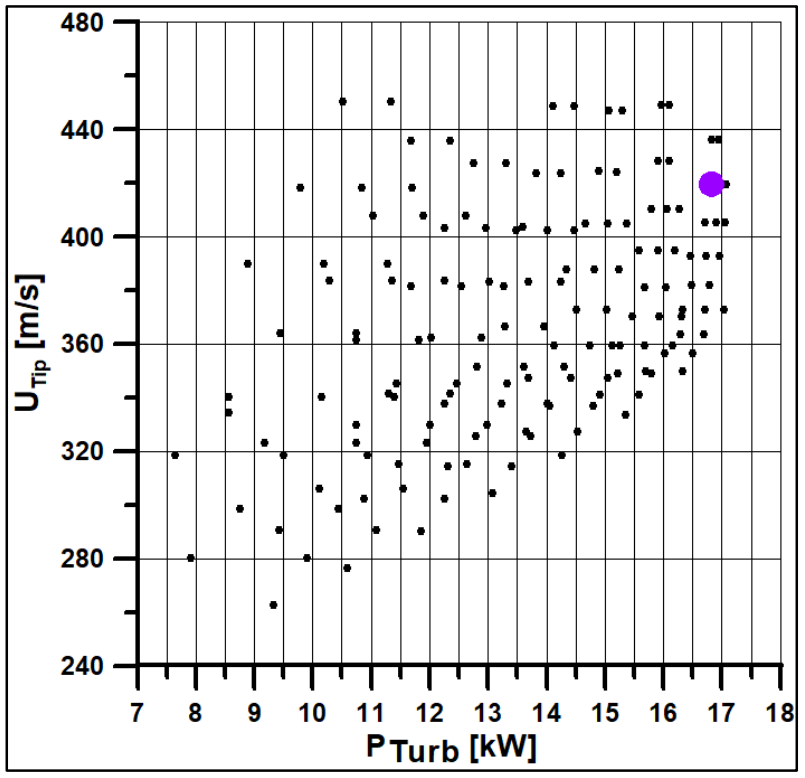

Figure 23. Turbine design space at 5000 RPM - WOT based on full exhaust mass flow

Table 5. Geometrical data of the selected turbine for hybrid layout

\begin{tabular}{|l|c|}
\hline Test Cases & Hybrid \\
\hline AVR $[-]$ & 1.3 \\
\hline$r_{p}[-]$ & 0.45 \\
\hline$\alpha_{2}\left[{ }^{\circ}\right]$ & 70 \\
\hline$\eta_{t s}[\%]$ & 73.52 \\
\hline $\mathrm{U}_{t i p}[\mathrm{~m} / \mathrm{s}]$ & 419.7 \\
\hline $\mathrm{D}_{\max }[\mathrm{m}]$ & 0.06 \\
\hline
\end{tabular}

It should be underlined that the design procedure was carried out by establishing a rotating speed of $120000 R P M$, which is in line of uptodated data of variable speed, permanent magnet generators [21]. So, limiting the tip speed at $420 \mathrm{~m} / \mathrm{s}$ also ensured a reduced turbine size, not exceeding a $7 \mathrm{~cm}$ tip diameter.

The related operating maps, in terms of pressure ratio versus corrected mass flow rate are reported in Figure 22. To the aim of a preliminary evaluation of the potential of the axial flow solution for the exhaust energy recovery turbine, the steady component matching was analyzed, with reference to the layout in Figure 21 by using Thermoflex ${ }^{\circledR}$ software. In a first phase, the same variable speed, fullload engine data already employed for the engine model calibration in Figure 4 - Figure 6 were introduced for estimating the available electric power from the generator and the one required by the motor Figure 25. 


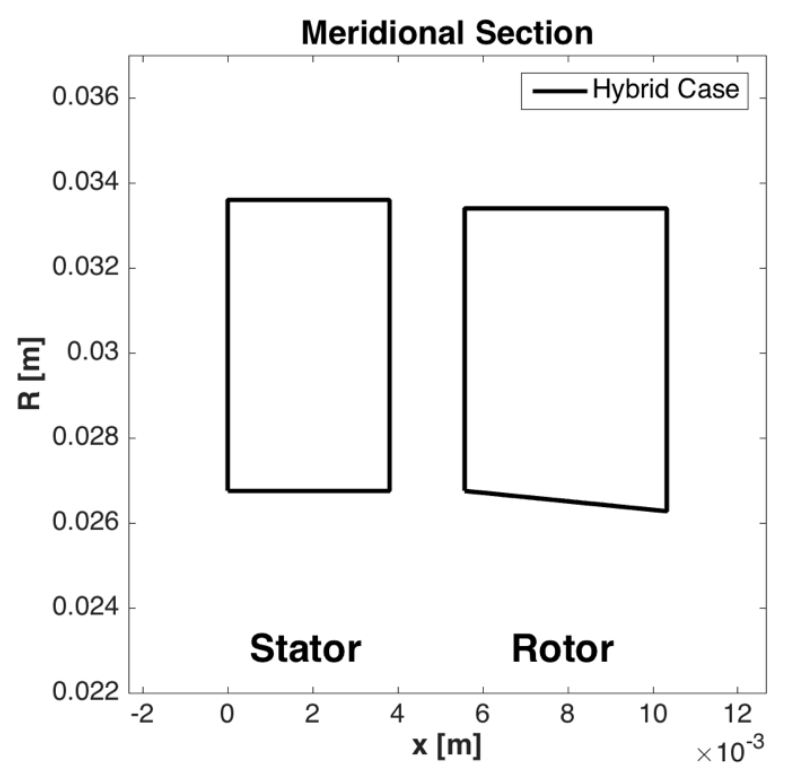

Figure 24. Turbine meridional section for the hybrid case

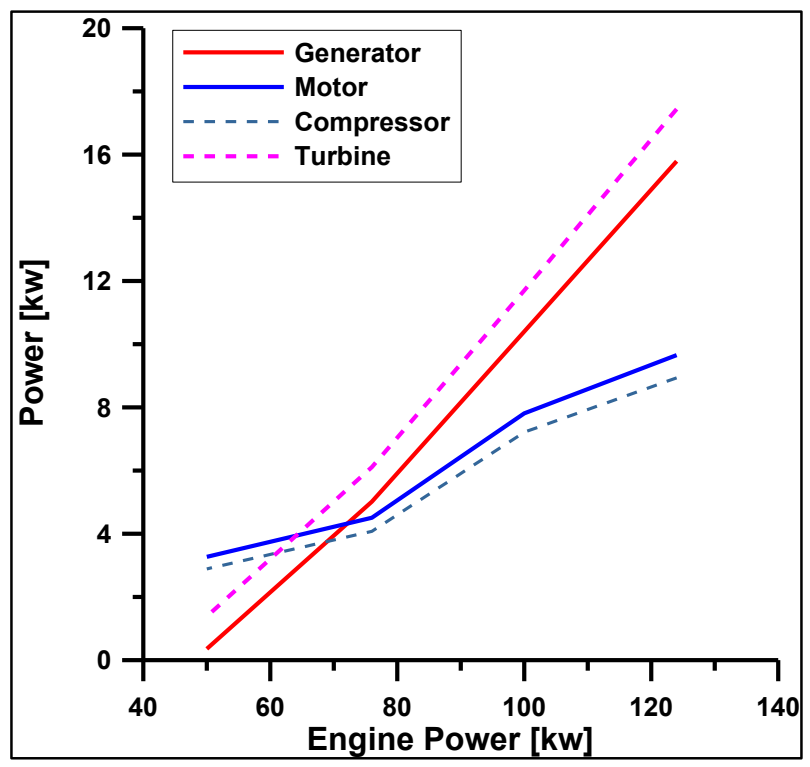

Figure 25. Turbine and Compressor shaft power and generator and motor electric power versus engine output

Although the result should be intended as cycle averaged data obtained with a control-volume approach, the curves in Figure 25 clearly show the existence of a wide region of engine power with a large excess in electricity generated with respect to the one required by the motor driving the compressor. The same diagram demonstrates that the results are affected by losses in both generator and motor, since higher differences occur between the turbine and compressor shaft power.

The encouraging perspectives that are outlined by in Figure 25 may be partly explained with the favorable trend of the axial flow turbine curves in Figure 22, if compared with those typical of a radial turbine in Figure 3. The main advantage consists in a better capacity to realize high expansion ratios also at reduced corrected speeds, so ensuring an acceptable power output also at low engine regimes. On the other hand, once checked the good response of the system in Figure 25, more refined computations can be addressed with unsteady flow solvers for a more accurate estimation of the hybrid - turbocharged engine in a wider operating range.

\section{Conclusions}

In this work, with the aim of improving the transient performance of a downsized turbocharged engine 1.6 $1 \mathrm{SI}$ for passenger car, an unconventional turbocharger turbine layout, say an axial-flow turbine, was investigated. The engine modeled that approaches the Ford Ecoboost is developed in Ricardo WAVE software and validated against data from published literature concerning the above-mentioned engine. The engine is turbocharged by means of a commercial turbocharger, namely the Garrett GT1548, whose maps (turbine and compressor) had been measured at National Laboratory of Engine Turbocharging Technology China. A meanline design algorithm based on Kacker-Okapuu correlation system, for preliminary turbine sizing and moment of inertia estimation, has been developed in MATLAB environment. Additionally, in order to perform comparisons among several turbine candidates with reasonable CPU time, an off-design prediction method for axial-flow turbines was developed and validated against data from open literature.

The meanline design code was exploited to generate several turbine candidates designed to work under the same boundary conditions and aimed at replacing the turbine of the commercial turbocharger considered. Two parallel paths have been followed developing the new proposal, i.e. a conventional turbine-compressor coupling and an electrically split turbocharger.

Concerning, the first case study, a parametric analysis (accomplished by means of the above-mentioned code) showed the conflicting trends of the two objectives, i.e. turbine efficiency and rotor moment of inertia. Hence, the region of the design space providing an inertia reduction (with respect to the commercial turbine) while guaranteeing the same level of turbine performance was further investigated by choosing suitable candidates based on best efficiency and moment of inertia reduction. Subsequently, turbine maps were generated by means of the off-design code and plugged into the engine model and the overall performance was evaluated on steady-state and transient performance view point.

Results show that, depending on the choice of design variables, the axial-flow layout might be a suitable alternative to the more conventional radial turbine, providing an inertia reduction too. In fact, steady-state calculations showed that two out of three investigated turbines were able to provide enough power to drive the compressor, without affecting the engine BFSC, and to maintain the same target torque curve achieved by means of the radial turbine, while providing a moment of inertia saving up to the $20 \%$ of the radial turbine.

Preliminary studies concerning the transient performance achieved with the new axial turbine showed that the inertia saving attained by means of the turbine layout change, along with favorable performance maps, was large enough to produce changes of the dynamic behavior of the system.

Concerning the "electrical coupling" case, a similar approach was used, although the tradeoff was established between different objectives, i.e. turbine size and power output; subsequently, the selected turbine performance map was generated by means of the offdesign performance prediction code. Results showed that in most of the investigated conditions, the available turbine output power is larger than that required by the compressor, suggesting that energy storage

Page 11 of 13 
either for boosting purpose or for auxiliaries' needs is actually an option.

Finally, it is worth pointing out that, in spite of the fact that no sophisticate technique was applied to the turbine design, the inertia improvements achieved are particularly encouraging. In fact, the selected turbine might represent a good baseline design for a multidisciplinary optimization aimed at the efficiency maximization and inertia minimization: in this scenario larger improvements are expected.

\section{References}

[1] O. Kutlar, H. Arslan and A. Calik, "Methods to improve efficiency of four stroke, spark ignition engines at part load," Energy Conversion and Management, vol. 46, no. 20, pp. 3202-3220, December 2005.

[2] N. Fraser, H. Blaxill, G. Lumsden and M. Bassett, "Challenges for Increased Efficiency through Gasoline Engine Downsizing," SAE Int. J. Engines, vol. 2, no. 1, pp. 991-1008, 2009.

[3] S. Shahed and K. Bauer, "Parametric Studies of the Impact of Turbocharging on Gasoline Engine Downsizing," SAE Int. J. Engines, vol. 2, no. 1, pp. 1347-1358, 2009.

[4] A. Assi, B. Chokor, M. Hammoud, A. Hallal, A. Shaer and B. Abdulhay, "Reducing the Turbo Lag of a Fixed Geometry Turbocharger," IJISET - International Journal of Innovative Science, Engineering \& Technology, vol. 4, no. 1, pp. 235-243, January 2017.

[5] T. Tetsui, "Application of TiAl in a Turbocharger for Passenger Vehicles," Advanced Engineering Materials, vol. 3, no. 5, pp. 307-310, May 2001.

[6] A. Feneley, A. Pesiridis and A. Andwari, "Variable Geometry Turbocharger Technologies for Exhaust Energy Recovery and Boosting-A Review," Renewable and Sustainable Energy Reviews, vol. 71, pp. 959-975, May 2017.

[7] Q. Zhang, P. Lu, P. Dimitriou, S. Akehurst, C. Copeland, M. Zangeneh, B. Richards and G. Fowler, "IMPLEMENTING FULL ELECTRIC TURBOCHARGING SYSTEMS ON HIGHLY BOOSTED GASOLINE ENGINES," in ASME. Turbo Expo: Power for Land, Sea, and Air, 2017.

[8] S. Rajoo and R. Martinez-Botas, "Mixed Flow Turbine Research: A Review," ASME. J. Turbomach., vol. 130, no. (4), pp. 044001-12, October 2008.

[9] S. Pischinger, M. Nijs, P. Adomeit, D. Seebach, B. Lehrheuer, T. Du n̈schede, A. Brassat, K. Wittek, T. Uhlmann, G. Schu rrmann, B. Ho pke, M. Ba hr, J. Serpa and A. Kuhlmann, "Trends-Spark Ignition," in Encyclopedia of Automotive Engineering, John Wiley \& Sons, Ltd, 2014, pp. 6-9.
[10] J. Lotterman, V. Kares, D. Jeckel and P. di Martino, "New Turbocharger Concept For Gasoline Engines," MTZ worldwide, vol. 73, no. 6, p. 54-58, June 2012.

[11] A. Pesiridis, A. Saccomanno, R. Tuccillo and A. Capobianco, "Conceptual Design of a Variable Geometry, Axial Flow Turbocharger Turbine," in SAE Technical Paper, Capri, 2017.

[12] A. Pesiridis, A. Ferrara, R. Tuccillo and H. Chen, "Conceptual Design of an Axial Turbocharger Turbine," in ASME. Turbo Expo: Power for Land, Sea, and Air, 2017.

[13] A. Pesyridis, A. Cappiello and R. Tuccillo, "Design of a Variable Geometry Axial-Inflow Turbine Turbocharger Equipped With a Diffuser-Collector System," in ASME. Turbo Expo: Power for Land, Sea, and Air, 2018.

[14] C. Weber, A. Brumley, D. Filipe, P. Whiston, A. Schamel and M. Wirth, "1.6 SCTI: The New EcoBoost DI-Turbo Engine with Central Direct Injection for Ford's Volume Carlines," in Aachener Kolloquium Fahrzeug- und Motorentechnik, Aachen, 2010.

[15] D. G. Ainley and G. C. R. Mathieson, "A Method of Performance Estimation for Axial Flow Turbines," British ARC R\&M 2974, 1951.

[16] O. Zweifel, "The Spacing of Turbo-Machine Blading, Especially with Large Angular Deflection," The Brown Boveri Review, vol. 32, pp. 436-444, December 1945.

[17] S. Kacker and U. Okapuu, "A Mean Line Prediction Method for Axial Flow Turbine Efficiency," ASME. J. Eng. Power, vol. 104, no. (1), pp. 111-119, 1982.

[18] J. Dunham and P. Came, "Improvements to the AinleyMathieson Method of Turbine Performance Prediction," ASME. J. Eng. Power, vol. 92, no. (3), pp. 252-256, 1970.

[19] M. Benner, S. Sjolander and S. Moustapha, "Influence of Leading-Edge Geometry on Profile Losses in Turbines at OffDesign Incidence: Experimental Results and an Improved Correlation," ASME. J. Turbomach., vol. 119, no. (2), pp. $193-$ 200, 1997.

[20] S. Moustapha, S. Kacker and B. Tremblay, "An Improved Incidence Losses Prediction Method for Turbine Airfoils," ASME. J. Turbomach, vol. 112, no. (2), pp. 267-276, 1990.

[21] D. Mikkelson, "15KW Small Turboelectric Power Generation System," 2006.

Page 12 of 13 


\section{Contact Information}

Contact details for the main author should be included here. Details may include mailing address, email address, and/or telephone number (whichever is deemed appropriate).

\section{Acknowledgments}

Energy balance of the engine with hybrid turbocharging equipment was computed with the Thermoflex ${ }^{\circledR}$ tool (Thermoflex. Inc.).

Turbocharged Engine was simulated by Ricardo Wave ${ }^{\circledR}$ software.

\section{Symbols}

$a$

$\boldsymbol{A}$

$A R$

AVR

$\boldsymbol{b}$

$b_{x}$

$I$

$\dot{m}$

o

$p$

$P$

$\boldsymbol{r}_{\boldsymbol{p}}$

$T$

$\alpha$

$\boldsymbol{\beta}$

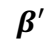

$\gamma$

$\boldsymbol{\eta}$

$\eta_{t s}$

$\phi$

$\psi$

$\mathbf{\Omega}$
Speed of sound

Area

Aspect Ratio

Axial Velocity Ratio

True chord

Axial chord

Rotor moment of inertia

Mass flow rate

Throat

Pressure

Power

Pressure-based reaction degree

Temperature

Flow angle in absolute reference frame

Flow angle in relative reference frame

Metal angle

Specific heat ratio

Blading efficiency

Total-to-static efficiency

Stagger angle

Efflux function

Rotational speed ex

turb

$x$

$\theta$

Apex
Quantity at stator outlet

Quantity at rotor inlet

Exit

Turbine

Axial direction

Tangential direction

Quantity referring to the stator (if not differently stated)

Quantity referring to the rotor

\begin{tabular}{|c|c|}
\hline SI & Spark Ignition \\
\hline BSFC & $\begin{array}{l}\text { Brake Specific Fuel } \\
\text { Consumption }\end{array}$ \\
\hline NA & Naturally Aspirated \\
\hline VGT & Variable Geometry Turbine \\
\hline VNT & Variable Nozzle Turbine \\
\hline BSR & Blade Speed Ratio \\
\hline AIROT & $\begin{array}{l}\text { Axial Inflow Radial Outflow } \\
\text { Turbine }\end{array}$ \\
\hline RIAOT & $\begin{array}{l}\text { Radial Inflow Axial Outflow } \\
\text { Turbine }\end{array}$ \\
\hline CFD & $\begin{array}{l}\text { Computational Fluid- } \\
\text { Dynamics }\end{array}$ \\
\hline WG & Waste Gate valve \\
\hline WOT & Wide Open Throttle \\
\hline BC & Boundary Conditions \\
\hline $\mathbf{A M}$ & Ainley and Mathieson \\
\hline KO & Kacker and Okapuu \\
\hline DC & Dunham and Came \\
\hline BSM & $\begin{array}{l}\text { Benner-Sjolander- } \\
\text { Moustapha }\end{array}$ \\
\hline MKT & $\begin{array}{l}\text { Moustapha-Kacker- } \\
\text { Tremblay }\end{array}$ \\
\hline TC & Tip Clearance \\
\hline
\end{tabular}

\section{Subscripts}

0/tot Total quantity

1 Quantity at stator inlet 